\title{
Caracterização do flúor insolúvel formado em dentifrícios a base de MFP/CaCO3
}

\section{Leonardo Libardi Pagotto*, Camila Coelho, Guilherme Caligaris, Jaime Aparecido Cury, Lisandro Pavie Cardoso}

\section{Resumo}

Não há estudo comprovando que o sal de fluoreto insolúvel formado em dentifrícios a base de MFP/CaCO3 seja fluoreto de cálcio (CaF2). Através de análise por difração de raios $\mathrm{X}$ não identificamos $\mathrm{CaF} 2$ em amostras de dentifrícios contendo diferentes concentrações de fluoreto insolúvel, sugerindo que outros sais insolúveis sejam formados.

\section{Palavras-chave:}

Dentifrício; Carbonato de cálcio; Fluoreto de cálcio; Difração de $R x$.

\section{Introdução}

No Brasil a maioria dos dentifrícios utilizados pela população tem como abrasivo o carbonato de cálcio $\left(\mathrm{CaCO}_{3}\right)$ (Ricomini Filho et. al., 2012). Por conterem cálcio $(\mathrm{Ca})$ no abrasivo, o sal de flúor agregado é monofluorfosfato de sódio (MFP $=\mathrm{Na}_{2} \mathrm{PO}_{3} \mathrm{~F}$ ). O MFP quando dissolvido libera no dentifrício 0 íon monofluorfosfato $\left(\mathrm{FPO}_{3}{ }^{2-}\right)$, no qual o flúor está ligado covalentemente ao radical fosfato e portanto não reage imediatamente com $\mathrm{Ca}^{2+}$ quando 0 dentifrício é formulado. Entretanto, durante o armazenamento, o íon MFP sofre hidrólise liberando íon flúor, o qual reage com os íons $\mathrm{Ca}^{2+}$ do abrasivo, formando sais insolúveis. Tem sido descrito que o sal insolúvel formado é $\mathrm{CaF}_{2}$ mas não há nenhum estudo na literatura que tenha caracterizado cristais de $\mathrm{CaF}_{2}$ nos dentifrícios a base de $\mathrm{MFP} / \mathrm{CaCO}_{3}$.

\section{Resultados e Discussão}

Amostras $(n=6)$ frescas do dentifrício à base de $\mathrm{MFP} / \mathrm{CaCO}_{3}$ mais vendido no Brasil (Sorriso dentes brancos, $1450 \mathrm{ppm}$ de flúor total) foram divididas em 4 grupos: 1) Recém adquirido; 2) Contendo $20 \%$ de fluoreto insolúvel (Fins); 3) $40 \%$ de Fins. e 4) $60 \%$ de Fins. Essas concentrações de Fins foram obtidas submetendo amostras do dentifrício fresco à $55^{\circ} \mathrm{C}$. Amostras de $10,0 \mathrm{~g} \quad( \pm 0,5 \mathrm{mg})$ de dentifrícios foram suspensas em $30 \mathrm{~mL}$ de água purificada e centrifugadas (3.000 g, $10 \mathrm{~min}$, à t.a.) para a precipitação do Fins. Os precipitados foram desidratados em dessecador a vácuo sob $\mathrm{CaCl}_{2}$ por $48 \mathrm{~h}$, fracionados para obtenção de granulometria uniforme $(\sim 15 \mu \mathrm{M})$ e analisados por difração de raios- $X$ (Difrator Phillips PW1880). As concentrações de flúor total $(F T=F S T+F I n s)$, flúor solúvel total (FST=íon MFP + íon F) foram determinadas com ISE e a porcentagem de Fins foi calculada.

Tabela 1. Concentração média $( \pm)$ de FT, FST e \% de Fins nas amostras de dentifrícios estudados

\begin{tabular}{|c|c|c|c|}
\hline \multicolumn{4}{|c|}{ ppm F } \\
\hline Dentifrício & FT & FST & \%FIns \\
\hline Fresco & $1430,2 \pm 32$ & $1401,6 \pm 24$ & 2,0 \\
\hline 20\% FIns & $1438,5 \pm 27$ & $1122,4 \pm 14$ & 22,0 \\
\hline 40\% Fins & $1415,1 \pm 46$ & $836,4 \pm 15$ & 40,9 \\
\hline 60\% FIns & $1445,7 \pm 34$ & $581,6 \pm 7$ & 59,7 \\
\hline
\end{tabular}

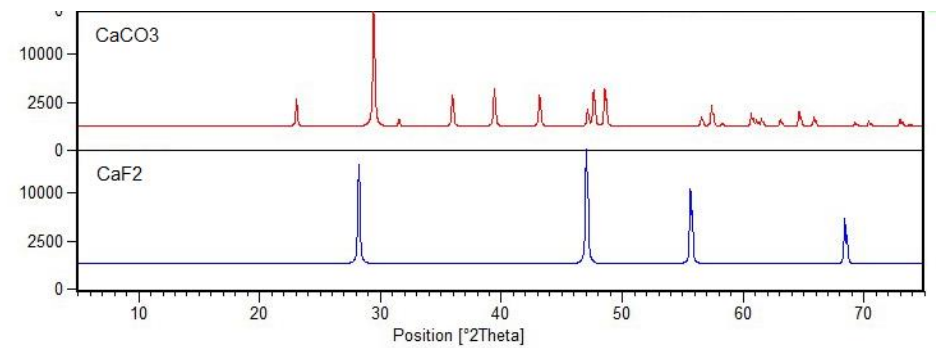

Figura 1. Espectro dos padrões de $\mathrm{CaCO}_{3}$ (vermelho) e $\mathrm{CaF}_{2}$ (azul).

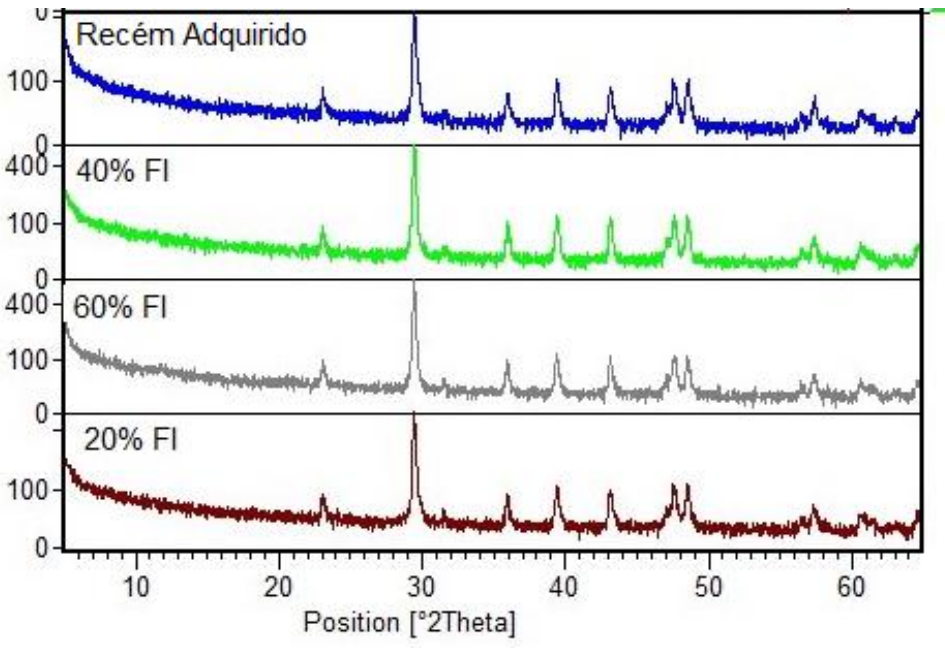

Figura 2. Espectro de Rx das amostras de dentifrício.

\section{Conclusões}

Os dados sugerem que o fluoreto insolúvel formado em dentifrício formulado com $\mathrm{MFP} / \mathrm{CaCO}_{3}$ não é $\mathrm{CaF}_{2}$.

\section{Agradecimentos}

Agradeço ao professor Jaime A Cury pelos ensinamentos, a aluna de PG Camila Coelho pelo acompanhamento, ao professor Lisandro Pavie Cardoso do IFGW pela análise de difração de raios $x$ e ao PIBIC pelo fomento a essa pesquisa.

Cury JA. Estabilidade do flúor nos dentifrícios brasileiros. RGO (Porto Alegre). 1986;34(5):430-2.

${ }^{2}$ Ricomini Filho AP, Tenuta LM, Fernandes FS, Calvo AF, Kusano SC, Cury JA. Fluoride concentration in the top-selling Brazilian toothpastes purchased at different regions. Braz Dent. 2012; 23:45-48. 